\title{
ОПТИЧЕСКИЕ СВОЙСТВА КВАНТОВЫХ ТОЧЕК CdS, СИНТЕЗИРОВАННЫХ ПРИ РАЗНЫХ КОНЦЕНТРАЦИЯХ РЕАГЕНТОВ
}

\author{
() 2018 Ю. С. Бездетко ${ }^{1}$ В. Г. Клюев ${ }^{2}$ В. Н. Фёклин ${ }^{1}$ \\ ${ }^{1}$ ВУНЦ ВВС «Военно-воздушная академия им. профессора Н. Е. Жуковского и Ю. А. Гагарина», \\ ул. Старых Большевиков, 54А, 394064 Воронеж, Россия \\ ${ }^{2}$ Воронежский государственный университет, Университетская пл., 1, 394018, Воронеж, Россия \\ e-mail:vgklyuev@rambler.ru
}

Поступила в редакцию 05.02.2018

\begin{abstract}
Аннотация. В работе приведены результаты исследования квантовых точек сульфида кадмия, синтезированных по золь-гель технологии в желатиновой матрице. Образцы были получены в ходе синтеза с разным содержанием исходных реагентов, концентрация которых изменялась от $2 \cdot 10^{-4}$ до 1.0 ат. \% относительно воды, содержащейся в реакторе. Кристаллическая решетка полученных квантовых точек $\mathrm{CdS}$ имеет кубическую структуру. Методами просвечивающей электронной спектроскопии, рентгеновской дифрактометрии и оптической спектроскопии определён размер квантовых точек, величина которого изменяется от 1 до 3.5 нм. Определены условия синтеза, при которых пленочные образцы квантовых точек $\mathrm{CdS}$ в желатиновой матрице имеют максимальную интенсивность люминесценции. Размер соответствующих квантовых точек CdS равен $d=2.1 \pm 0.2$ нм.

При увеличении размеров квантовых точек $\mathrm{CdS}$ максимумы полос люминесценции смещаются в длинноволновую область спектра в соответствии с квантово-размерным эффектом.

Изменение диаметра квантовых точек от 1 до 2.1 нм сопровождается увеличением интенсивности люминесценции до максимального значения. Сопоставлены экспериментальная средняя скорость увеличения интенсивности люминесценции и такая же средняя скорость, рассчитанная в предположении, что интенсивность люминесценции образца пропорциональна двум параметрам: количеству центров люминесценции в квантовых точках пропорциональному объёму квантовых точек и количеству КТ в образце. Оказалось, что экспериментальная средняя скорость увеличения интенсивности люминесценции превышает рассчитанную.
\end{abstract}

Ключевые слова: квантовые точки, сульфид кадмия, спектры люминесценции, золь-гель технология.

DOI: https://doi.org/10.17308/kcmf.2018.20/473

\section{ВВЕДЕНИЕ}

В настоящее время формирование квантовых точек (КТ) в полимерных матрицах на основе золь-гель технологии получило широкое распространение [16]. Применение в качестве матрицы желатины позволяет синтезировать квантовые точки размером от 1 нм и более. Например, образцы, содержащие квантовые точки сульфида кадмия (КT CdS), синтезированные с помощью золь-гель технологии, обладают люминесценцией в видимой области спектра с достаточно высоким квантовым выходом люминесценции при комнатной температуре. Представляет интерес исследование зависимости оптических, в том числе люминесцентных свойств KT CdS, синтезированных в широком диапазоне варьирования кон- центраций исходных реагентов. Особенно на ранних стадиях роста нанокристаллов. Это открывает новые возможности применения оптических свойств наноструктурированного $\mathrm{CdS}$ в видимом и ультрафиолетовом диапазоне оптического спектра.

Целью данной работы является изучение размерных структурных и оптических эффектов в квантовых точках сульфида кадмия, синтезированных в широком диапазоне варьирования концентраций исходных реагентов.

\section{ЭКСПЕРИМЕНТАЛЬНАЯ ЧАСТЬ}

Исследуемые образцы квантовых точек CdS

Исследованы структурные и оптические свойства KT CdS, стабилизированных в желатине. Об- 
разцы синтезировали по золь-гель технологии путем двухструйного сливания водных растворов исходных реагентов $\mathrm{Na}_{2} \mathrm{~S}$ и $\mathrm{CdBr}$ с помощью перистальтического насоса в реактор с поддерживаемой температурой $40{ }^{\circ} \mathrm{C}$, содержащий $2.5 \%$-й раствор инертной фотографической желатины в дистиллированной воде [1-5]. Смешивание вышеупомянутых компонентов происходило роторной мешалкой, вращающейся со скоростью 300 об/мин. Скорость поступления растворов была постоянной и составляла 40 мл/мин.

Было проведено 11 синтезов, в ходе которых получено 11 образцов. Концентрация синтезированного $\mathrm{CdS}$ относительно воды составляла $\mathrm{C}_{\mathrm{CdS}}=0.000198$ ат. \% (образец номер 1); 0.000625 ат. \% (2); 0.00198 ат. \% (3); 0.00625 ат. \% (4); 0.0198 ат. \% (5); 0.03125 ат. \% (6); 0.0625 ат. \% (7); 0.125 ат. \% (8); 0.25 ат. \% (9); 0.5 ат. \% (10); 1 ат. \% (11). Таким образом, концентрация исходных реагентов от 1-го до 11-го образца увеличивалась в $5 \cdot 10^{3}$ раз.

Образцы поливались на стеклянные пластинки одинакового размера и формы для измерения спектров поглощения и спектров люминесценции.

\section{МЕТОДИКИ ИССЛЕДОВАНИЙ}

Сведения о кристаллической структуре синтезированных образцов получали на дифрактометре Empyrean B.V. (PANalytical, Нидерланды) с использованием излучения $K \alpha_{1}$ меди.

Средние размеры КТ, их дисперсию в ансамбле определяли по данным электронной микроскопии, полученным с помощью просвечивающего электронного микроскопа Libra 120 (Carl Zeiss, Германия).

Для измерения спектров оптического поглощения KT $\mathrm{CdS}$ использовали спектрофотометр USB2000+ с источником излучения USB-DT (Ocean Optics, USA).

Люминесцентные исследования проводились с помощью автоматизированного спектрального комплекса на базе дифракционного монохроматора МДР-23 (ЛОМО). Источником возбуждения фотолюминесценции в видимой области служил светодиодный модуль HPL-H77GV1BT-V1 с излучением на длине волны 380 нм.

\section{РЕЗУЛЬТАТЫ И ИХ ОБСУЖДЕНИЕ \\ Структурные характеристики квантовых точек $\mathrm{CdS}$}

Полученные образцы охарактеризованы методами просвечивающей электронной микроскопии
ПЭМ (рис. 1) и рентгеновской дифракции (рис. 2). На рис. 1 представлены ПЭМ-изображения образцов КТ с разным содержанием CdS относительно воды $C_{\mathrm{CdS}}=0.00625$ ат. \% (рис. $1 a$ ), 0.0625 ат. \% (рис. $1 b$ ), 0.25 ат. \% (рис. $1 c$ ) и гистограммы, позволяющие определить средний размер КT CdS. Гистограммы, приведенные справа на рис. 1, показывают, что с увеличением концентрации исходных реагентов увеличиваются и размеры КТ. Средний размер КT CdS изменяется от 1.5 до 2.5 нм. Как видно из ПЭМ-изображений, часть КТ находятся очень близко друг к другу или их проекции накладываются друг на друга, что затрудняет определение их точного размера.

По данным рентгеновской дифракции установлена кристаллическая структура синтезированных KT CdS. Для $C_{\mathrm{CdS}}=0.25$ ат. \% (образец 9) дифрактограмма приведена на рис. 2. Кривая представляет
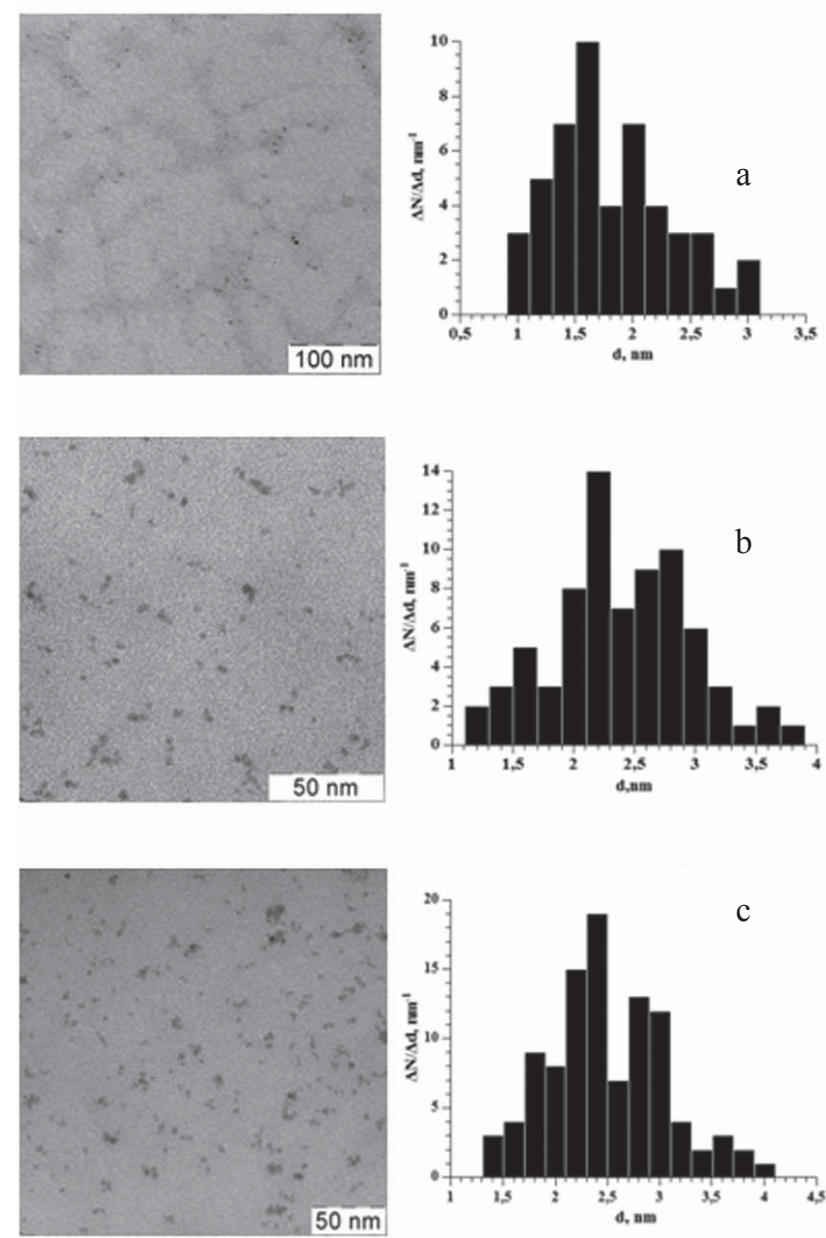

Рис. 1. ПЭМ-изображения квантовых точек $\mathrm{CdS}$ и результаты их анализа для образцов $C_{\mathrm{CdS}}=0.00625$ ат. $\%(a), 0.0625$ ат. $\%(б), 0.25$ ат. $\%(6)$

[Fig. 1. The TEM image of the QDs CdS and the results of their analysis for samples $C_{\mathrm{CdS}}=0.00625$ at. \% (a), 0.0625 at. $\%(b), 0.25$ at. $\%(c)]$ 


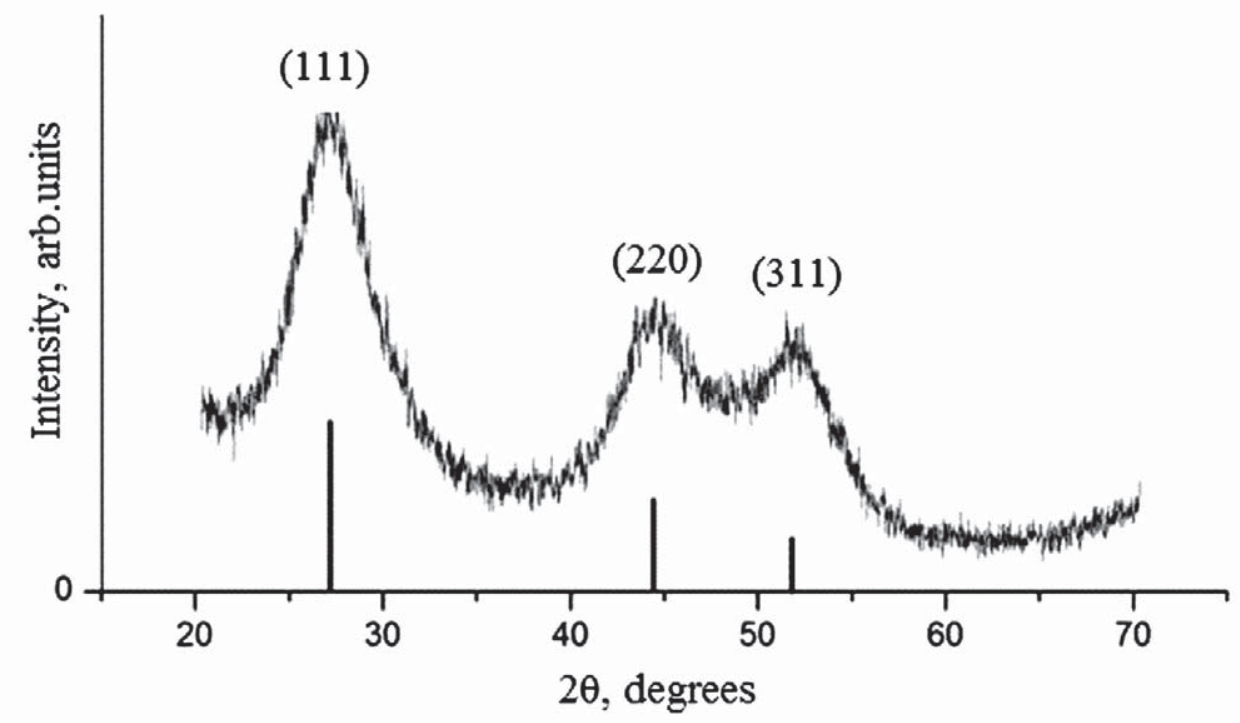

Рис. 2. Рентгеновская дифрактограмма квантовых точек $\mathrm{CdS}$ образца $C_{\mathrm{CdS}}=0.25$ ат. \%

[Fig. 2. XRD pattern of the QDs CdS for sample $C_{\mathrm{CdS}}=0.25$ at. \%.]

собой уширенные рефлексы, соответствующие кубической решетке $\mathrm{CdS}$. Уширение рефлексов рентгеновской дифракции вызвано малым размером частиц в исследуемых ансамблях. Размер КТ вычислялся по формуле Шеррера $d=0.89 \lambda /\left(\beta \cos \theta_{B}\right)$ [4], где $d$ - средний диаметр КТ, $\lambda$ - длина волны излучения $\mathrm{CuK \alpha} \alpha_{1}(1.54056 \AA), \beta$ (в радианах) - полуширина пика и $\theta_{B}-$ брэгговский угол рефлексов рентгеновской дифракции. Для пика (111) KT CdS кристаллиты имеют средний размер 3.2 нм.

\section{Оптические свойства квантовых точек $\mathrm{CdS}$}

По минимуму вторых производных спектров поглощения $d^{2} D / d(\hbar \omega)^{2}$ определяли положение характерных особенностей для каждого образца, которые соответствуют значениям энергий экситонных переходов или ширинам эффективных запрещенных зон проводимости КT CdS.

С помощью формулы Брюса [7] были оценены средние размеры квантовых точек:

$$
\Delta E=\frac{\hbar^{2} \pi^{2}}{2 \mu R^{2}}-\frac{1.78 e^{2}}{\varepsilon R}-0.248 E_{R y},
$$

где $\Delta E=\hbar \omega-E_{g}, E_{g}=2.4$ эВ [8], $R$ - радиус КТ в нм, $m_{e}^{*}=0.19 m_{0}$ и $m_{h}^{*}=1.16 m_{0}-$ эффективные массы электрона и дырки для $\mathrm{CdS}$ [8], $\varepsilon=5.7$ [10], $E_{R y}^{*}=\varepsilon^{4} / 2 \varepsilon^{2} \hbar^{2}\left(m_{e}^{*-1}+m_{h}^{*-1}\right)$ [8]- эффективная энергия Ридберга.

На рис. 3 представлена зависимость диаметра квантовых точек $\mathrm{CdS}$ от концентрации $\mathrm{CdS}$ относительно воды $\left(C_{\mathrm{CdS}}\right.$ aт. \%). На данном рисунке кривая 1 представляет собой усредненную кривую для значений, полученных по данным из оптических спектров поглощения (образцы 1-11), а кривая 2 - усредненная кривая для значений, полученных из ПЭМ-изображений (образцы $2,4,7,9)$ и рентгеновской дифракции (образцы 2, 4, 9). Кривая 2 аппроксимирована функцией:

$$
y=3.4 e^{0.3 x} \text { или } d=3.4 e^{\lg C_{\text {cas }}} .
$$

Как видно из данного рисунка, для размеров KT CdS $1 \div 2$ нм данные, полученные с помощью оптического поглощения, в $1.5 \div 2$ раза больше, чем размеры КТ, полученные с помощью ПЭМизображений и рентгеновской дифракции. Таким образом, для размеров КТ, меньших 3.5 нм, оптическое поглощение дает большую погрешность для определения диаметров КТ, что согласуется с литературными данными $[5,9]$. Поэтому в дальнейшем использовались данные, полученные с помощью ПЭМ-изображений и рентгеновской дифракции.

Так как не для всех образцов получены ПЭМизображения и рентгеновская дифракция, то диаметры всех образцов были рассчитаны по формуле (1) и представлены в табл. 1. Обращает на себя внимание тот факт, что при увеличении количества исходных реагентов на 3.5 порядка, размер КТ $\mathrm{CdS}$ увеличивается всего в три раза.

На рис. 4 приведены нормированные спектры люминесценции исследуемых образцов. Видно, что 


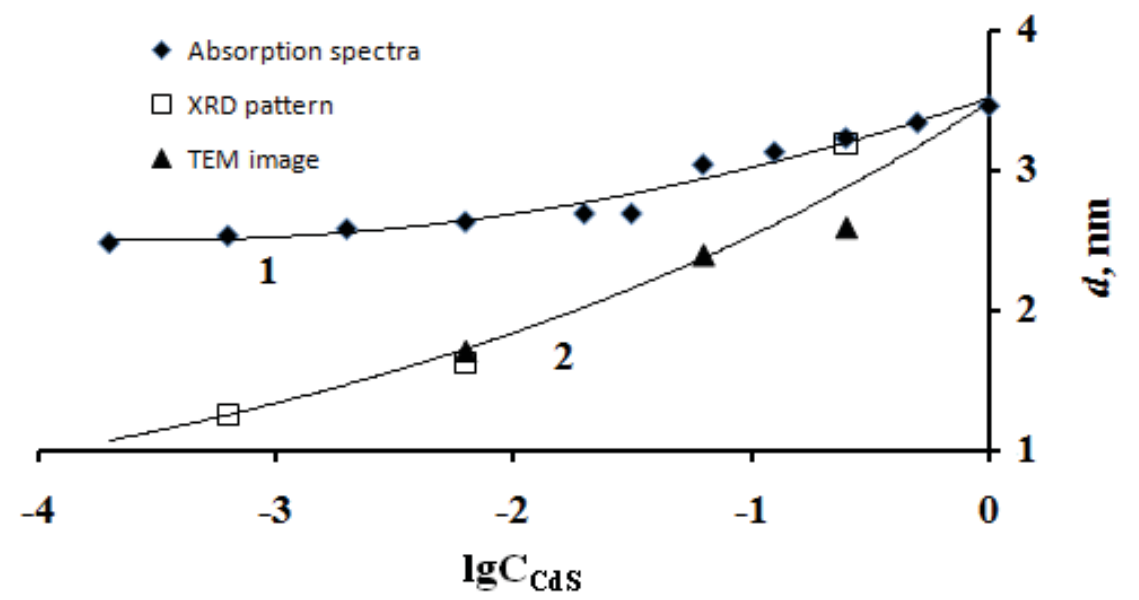

Рис. 3. Зависимость диаметра квантовых точек $\mathrm{CdS}$ от концентрации $\mathrm{CdS}$ относительно воды

[Fig. 3. Dependence of the diameter QDs CdS from the CdS concentration relatively to water]

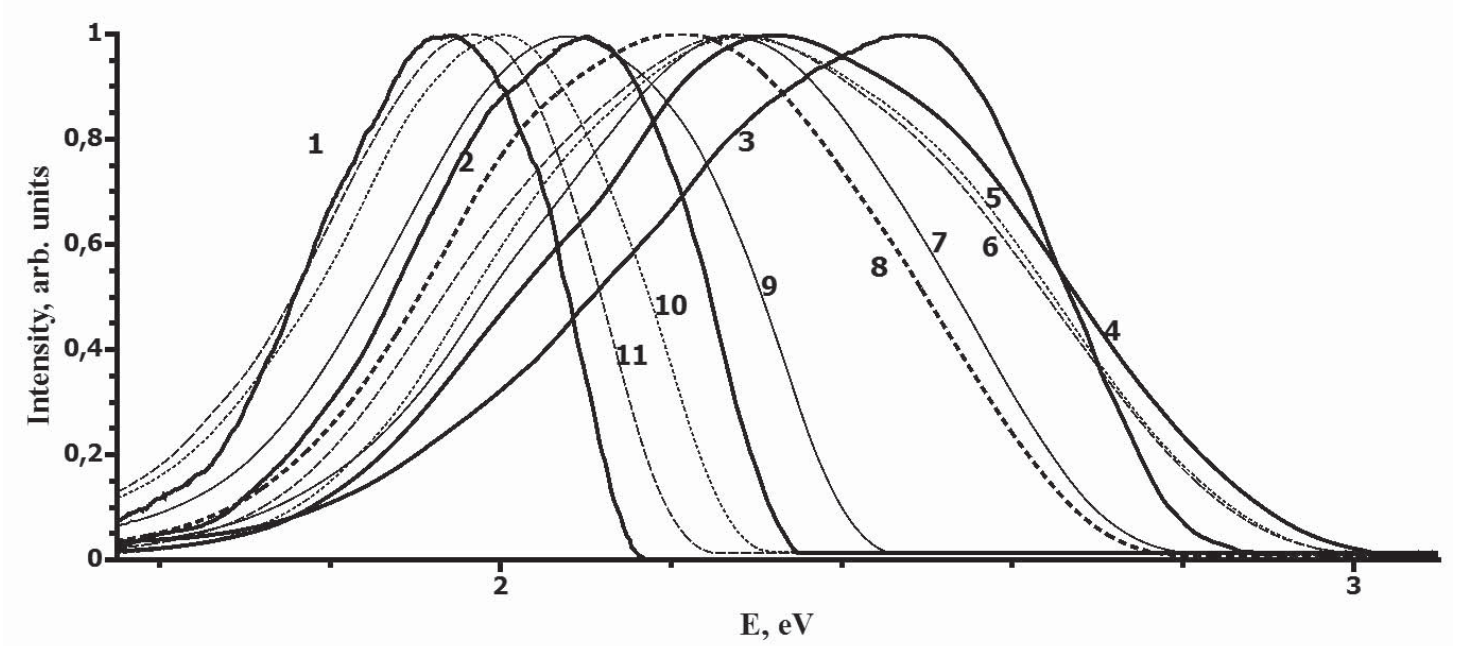

Рис. 4. Нормированные спектры люминесценции образцов КT CdS с содержанием CdS относительно воды [Fig. 4. The standardized luminescence spectra of the samples QDs CdS with the CdS concentration relatively to water]

Таблица 1. Экспериментальные данные для синтезированных образцов КT CdS [Table 1. Experimental data for synthesized samples of QDs CdS]

\begin{tabular}{|c|c|c|c|c|c|c|c|c|c|c|c|}
\hline Sample No & 1 & 2 & 3 & 4 & 5 & 6 & 7 & 8 & 9 & 10 & 11 \\
\hline$C_{\text {Cds }}$, at. \% & 0.000198 & 0.000625 & 0.00198 & 0.00625 & 0.0198 & 0.0313 & 0.0625 & 0.125 & 0.25 & 0.5 & 1.0 \\
\hline$d, \mathrm{~nm}$ & 1.1 & 1.2 & 1.4 & 1.7 & 2.0 & 2.1 & 2.4 & 2.6 & 2.9 & 3.2 & 3.5 \\
\hline$\lambda_{\max }$, nm & 640 & 590 & 498 & 533 & 543 & 544 & 545 & 563 & 595 & 614 & 627 \\
\hline$I_{\max }$ arb. un. & 0.002 & 0.007 & 0.131 & 0.324 & 0.839 & 1 & 0.562 & 0.554 & 0.053 & 0.051 & 0.028 \\
\hline
\end{tabular}




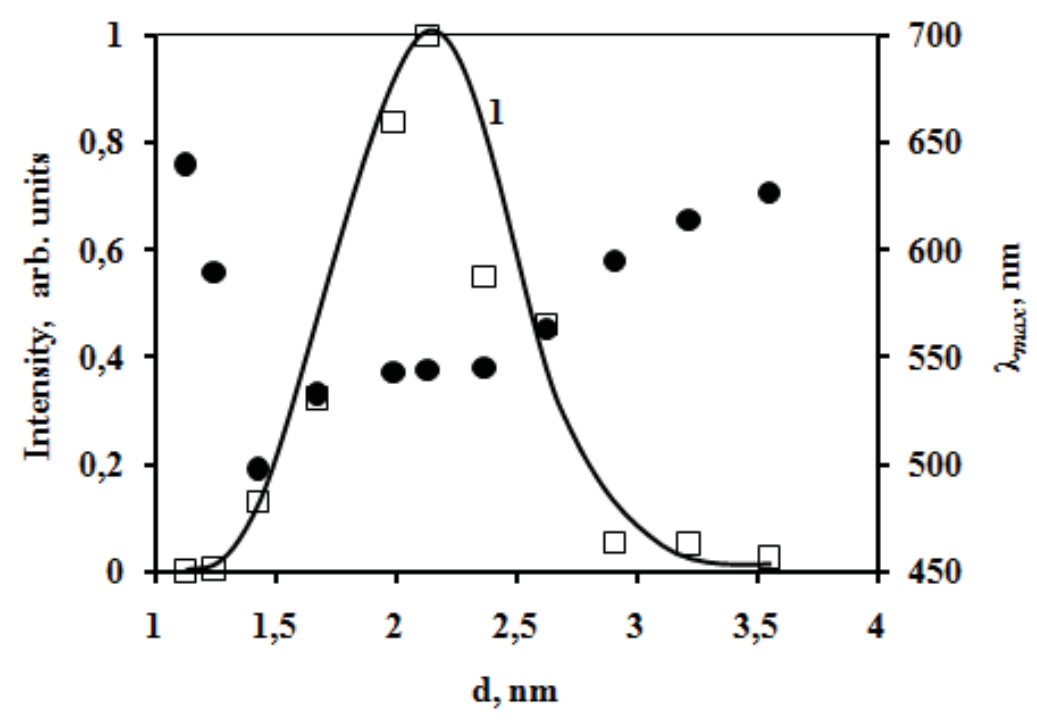

Рис. 5. Зависимость интенсивности люминесценции (кривая 1) и длины волны (•) в максимуме полосы люминесценции от размера КT CdS

[Fig. 5. Dependence of luminescence intensity (curve 1) and wavelength ( $\bullet$ ) in the maximum of the luminescence band from the CdS QDs size]

при возрастании размеров КT CdS от 1.1 нм до 2 нм (кривые 1-4), полоса люминесценции смещается в коротковолновую область. При этом увеличивается полуширина полосы люминесценции. Начиная с 5-го образца, спектр люминесценции смещается в длинноволновую область. При диаметрах KT CdS равных 3 нм и более (начиная с 9 кривой рис. 4) спектр начинает сужаться.

На рис. 5 представлены зависимости интенсивности люминесценции (кривая 1) и длины волны $(\bullet)$ в максимуме полосы люминесценции от размера KT CdS. У образцов с размерами КТ $\sim 2$ нм наблюдается наибольшая интенсивность люминесценции с максимумом при $\lambda=550 \mathrm{Hм}$.

\section{ОБСУЖДЕНИЕ РЕЗУЛЬТАТОВ}

1. Определены условия синтеза, при которых пленочные образцы KT CdS в желатиновой матрице имеют максимальную интенсивность люминесценции. Размер соответствующих KT CdS paвен $d=2.1 \pm 0.2 \mathrm{Hм}$.

2. Интенсивность люминесценции КТ CdS диаметром 2.1 нм больше интенсивности люминесценции КТ CdS диаметром 1.1-1.2 нм примерно в 200 раз. Предположим, что число центров люминесценции для КТ пропорционально объёму нанокристалла. За счет увеличения размера КT CdS от 1.1 нм до 2.1 нм объём, и, следовательно, число центров люминесценции увеличивается в 7 раз. С ростом количества реагентов для синтеза число КТ
$\mathrm{CdS}$ в образце увеличивается в 20 раз. Таким образом, число центров люминесценции в целом должно увеличиться примерно в 140 раз. Соответственно и интенсивность люминесценции тоже должна увеличиться в 140 раз. Из эксперимента следует (табл. 1), что от 1-го до 6-го образца интенсивность люминесценции возросла в 200-300 раз. То есть больше, чем появилось центров люминесценции. Если учесть, что кроме центров люминесценции в кристалле существуют центры безызлучательной рекомбинации (например, оборванные связи на поверхности), то следует заключить, что формирование центров излучательной и безызлучательной рекомбинации происходит не пропорционально массе а, следовательно, объёму КТ. Этот вопрос требует дополнительного изучения.

При размере KT CdS больше чем 2.2 нм интенсивность люминесценции быстро уменьшается, повидимому, из-за увеличения доли безызлучательной деградации электронных возбуждений и процессов рассеяния и перепоглощения.

Выражаем благодарность ЦКПНО ВГУ за помощь в измерении дифрактограмм и ПЭМ изображений образиов.

\section{СПИСОК ЛИТЕРАТУРЫ}

1. Клюев В. Г., Фам Тхи Хаи Мьен, Бездетко Ю. С. // Конденсированные среды и межфазные границы, 2014, т. 16 , № 1, с. $27-31$. 
2. Бездетко Ю. С., Клюев В. Г. // Вестник ВГУ. Серия: Физика. Математика, 2014, № 1, с. 5-9.

3. Овчинников О. В. Патент РФ № 2013127444/05, 2013.

4. Овчинников О. В., Смирнов М. С., Шапиро Б. И., Шатских Т. С., Перепелица А. С., Королев Н. В. // ФТП, 2015 , т. 49, № 3, с. 385-391. DOI:10.1134/ S1063782615030173

5. Korolev N. V., Smirnov M. S., Ovchinnikov O. V., Shatskikh T. S. // Physica E, 2015, vol. 68, pp. $159-163$. DOI: https://doi.org/10.1016/j.physe.2014.10.042
6. Khodadadi B., Bordbar M. \& Yeganeh-Faal A. // J. Sol-Gel Sci Technol, 2016, vol. 77, № 3, pp 521-527. DOI: https://doi.org/10.1007/s10971-015-3877-z

7. Алиев Ф. Ф., Джафаров М. Б., Эминова В. И. // ФTП, 2010, т. 44, № 6, с.749. DOI: 10.1134/ S1063782610060059

8. Brus L. E. // J. Chtm. Phys., 1984, vol. 80, pp. 44034409.

9. Lippens P. E., Lannoo M. // Phys. Rev. B, 1989, vol. 39, № 15, pp. 10935-10942. DOI: https://doi. org/10.1103/PhysRevB.39.10935

\title{
OPTICAL PROPERTIES OF CdS QUANTUM DOTS SYNTHESIZED AT DIFFERENT CONCENTRATIONS OF REAGENTS
}

\author{
(C) 2018 Yu. S. Bezdetko ${ }^{1}$, V. G. Klyuev², V. N. Feklin ${ }^{1}$ \\ ${ }^{1}$ Military Educational and Scientific Center of the Air Force «N.E. Zhukovsky and Y.A. Gagarin Air Force \\ Academy»54A Staryh Bol'shevikov str., 394064 Voronezh, Russia \\ ${ }^{2}$ Voronezh State University, 1 Universitetskaya pl., 394018, Voronezh, Russia \\ e-mail:vgklyuev@rambler.ru
}

Received 05.02.2018

\begin{abstract}
The paper presents the results of the investigation of quantum dots of cadmium sulfide synthesized by sol-gel technology in a gelatin matrix. Samples were obtained with different contents of the initial reagents. The concentrations were varied from $2 \cdot 10^{-4}$ atom $\%$ up to 1.0 atom $\%$ relative to the water contained in the reactor. The crystal lattice of the CdS quantum dots has a cubic structure. Using the methods of transmission electron spectroscopy, X-ray diffractometry and optical spectroscopy, the size of quantum dots have determined. The values of which varies from $1 \mathrm{~nm}$ to $3.5 \mathrm{~nm}$. The synthesis conditions are determined for films of QDs CdS samples in the gelatin matrix which have a maximum luminescence intensity. The size of the corresponding QDs CdS is $d=2.1 \pm 0.2 \mathrm{~nm}$.

The luminescence band maxima shift to the long-wavelength region of the spectrum when the dimensions of the CdS quantum dots increase in accordance with the quantum-size effect.

The change in the diameter of quantum dots from $1 \mathrm{~nm}$ to $2.1 \mathrm{~nm}$ is accompanied by an increase in the luminescence intensity to a maximum value. The experimental average rate of increase in the luminescence intensity was comparisoned with the same average rate calculated on the assumption that the luminescence intensity of the sample is proportional to two parameters: the number of luminescence centers in QDs, which proportional to the volume of QD, and the amount of QD in the sample. It was found that the experimental average rate of increase in the luminescence intensity have exceeded the calculated.
\end{abstract}

Keywords: quantum dots, cadmium sulfide, luminescence spectra, sol-gel technology.

DOI: https://doi.org/10.17308/kcmf.2018.20/473

\section{ACKNOWLEDGMENTS}

The results of the experiment (TEM image and XRD pattern) were obtained using the equipment of the Center for Collective Use of Scientific Equipment of Voronezh State University

\section{REFERENCES}

1. Klyuev V. G., Fam Thi Hai M'en, Bezdetko Yu. S. Condensed Matter and Interphase, 2014, vol. 16, no. 1, pp. 27-31. Available at: http://www.kcmf.vsu.ru/resources/ t_16_1_2014_005.pdf (in Russ.) 
2. Bezdetko Yu. S., Klyuev V. G. Proceedings of Voronezh State University. Series: Physics. Mathematics, 2014, no. 1, pp. 5-9. Available at: http://www.vestnik.vsu.ru/pdf/ physmath/2014/01/2014-01-01.pdf (in Russ.)

3. Ovchinnikov O. V.Patent of the RF. no. 2013127444/05, 2013.

4. Ovchinnikov O. V., Smirnov M. S., Shapiro B. I., Shatskih T. S., Perepelica A. S., Korolev N. V. Semiconductors, 2015, vol. 49, no. 3, pp. 385-391. DOI:10.1134/ S1063782615030173

5. Korolev N. V., Smirnov M. S., Ovchinnikov O. V., Shatskikh T. S. Physica E, 2015, vol. 68, p. 159-163. DOI: https://doi.org/10.1016/j.physe.2014.10.042
6. Khodadadi B., Bordbar M. \& Yeganeh-Faal A. J. Sol-Gel Sci Technol, 2016, vol. 77, no. 3, pp 521-527. DOI: https://doi.org/10.1007/s10971-015-3877-z

7. Aliev F. F., Dzhafarov M. B., Jeminova V. I. Semiconductors, 2010, vol. 44, no. 6, pp.749. DOI: $10.1134 /$ S1063782610060059

8. Brus L.E. J. Chtm. Phys., 1984, vol. 80, pp. $4403-$ 4409. DOI:http://dx.doi.org/10.1063/1.447218

9. Lippens P. E., Lannoo M. Phys. Rev. B, 1989, vol. 39, no. 15, pp. 10935-10942. DOI: https://doi.org/10.1103/ PhysRevB.39.10935
Клюев Виктор Григорьевич - д. ф.-м. н., профессор кафедры оптики и спектроскопии, Воронежский государственный университет; тел.: +7(473) 2208780, e-mail: vgklyuev@rambler.ru

Бездетко Юлия Сергеевна - преподаватель кафедры физики и химии, ВУНЦ ВВС «ВВА им. проф. Н. Е. Жуковского и Ю. А. Гагарина»; тел.: +7(920) 4655944, e-mail:julfiz@yandex.ru

Фёклин Виктор Николаевич - к. ф.-м. н., доцент кафедры физики и химии, ВУНЦ ВВС «ВВА им. профессора Н. Е. Жуковского и Ю. А. Гагарина»; тел.: $+7(905) 6535496$
Victor G. Klyuev - Dr. Sci. (Phys.-Math.), Professor of the Optics and Spectroscopy Department, Voronezh State University; tel.: +7(473) 2208780, e-mail:vgklyuev@rambler.ru

Yulia S. Bezdetko - Lecturer of the Physics and Chemistry Department, Military Educational and Scientific Center of the Air Force «N. E. Zhukovsky and Y. A. Gagarin Air Force Academy»; tel.: +7(920) 4655944, e-mail:julfiz@yandex.ru

Viktor N. Feklin - Cand. Sci. (Phys.-Math.), Associate Professor of Physics and Chemistry Department, MESC AF «N. E. Zhukovshky and Y. A. Gagarin Air Force Academy»; tel.: $+7(905) 6535496$ 